\title{
Minimally processed and ultra-processed food daily consumption on the transition of nutritional status to obesity: a cross-sectional study
}

Leonardo Santos Lopes da Silva ( $\sim$ leonardosis@usp.br)

University of São Paulo

Pedro Pugliesi Abdalla

University of São Paulo

Lucimere Bohn

University of Porto

Rafael Gavassa de Araújo

Paulista University

Daniel de Freitas Batalhão

Paulista University

Ana Cláudia Rossini Venturini

University of São Paulo

Anderson dos Santos Carvalho

Paulista University

Michael Duncan

Coventry University

Jorge Mota

University of Porto

Dalmo Roberto Lopes Machado

University of São Paulo

\section{Research Article}

Keywords: Overweight, Metabolic Diseases, Nutrition Assessment, Body weight, Food quality

Posted Date: February 25th, 2022

DOI: https://doi.org/10.21203/rs.3.rs-1293284/v1

License: (c) (1) This work is licensed under a Creative Commons Attribution 4.0 International License.

Read Full License 


\section{Abstract}

\section{Background}

The role of food type consumption on nutritional status (NS) transition from overweight (OW) to obesity $(\mathrm{OB})$, represents a higher risk in the development of chronic diseases, morbidity, premature mortality, and health services burden compared to normal weight to OW. In this sense, minimally and ultra-processed foods can impact on NS transition. However, the influence of quantity consumption has not yet been investigated. We aimed to investigate the magnitude of the impact of ultra-processed food and minimally processed food consumption in the change of NS from OW to OB.

\section{Methods}

We included 15.024 participants (9.618 OW [body mass index $25.0-29.9 \mathrm{~kg} / \mathrm{m}^{2}$ ], 5.406 OB [body mass index $\geq 30 \mathrm{~kg} / \mathrm{m}^{2}$ ]) with age ranging from 18 to 59 years-old from the 2019 baseline survey of the Surveillance of Risk Factors and Protection for Chronic Diseases by Telephone Survey (VIGITEL). Minimally processed and ultra-processed food daily consumption and other confounding variables (age, sex, scholarity, physical activity, hypertension, and diabetes) were measured. Binary logistic regression analyzes the magnitude of the impact of ultra-processed food and minimally processed food consumption in the change of $\mathrm{OW}$ to $\mathrm{OB}$. The odds ratio $(\mathrm{OR})$ of transition (OW to $\mathrm{OB}$ ) was calculated.

\section{Results}

In general, minimally processed food $\left(1^{\text {st }}=1_{[\text {food } / \text { day }]} ; 2^{\text {nd }}=6_{[\text {food } / \text { day }]} ; 3^{\text {rd }}=7_{[\text {food } / \text { day }]} ; 4^{\text {th }}=8_{[\text {food } / \text { day }]}\right)$ presented higher quartile values compared to ultra-processed food $\left(1^{\text {st }}=1_{\text {[food } / \text { day] }} ; 2^{\text {nd }}=1_{\text {[food } / \text { day] }}\right.$; $3^{\text {rd }}=2_{[\text {food } / \text { day }]} ; 4^{\text {th }}=4_{[\text {food } / \text { day }]}$. For each minimally processed food consumed, there was a $-5.9 \%$ chance of NS transition to OB. In this sense, the higher quartile $\left(4^{\text {th }}\right)$ of minimally processed food consumption represents less chance of the NS transition to OB (OR: $-47.2 \% ; p<0.001)$. On the other hand, each ultraprocessed food consumed presented a chance of $3.7 \%$ of NS transition to OB. Therefore, higher consumption of ultra-processed food $\left(4^{\text {th }}\right.$ quartile) shows higher chance of the NS transition to OB (OR: $+14.8 \%$; $p<0.001)$.

\section{Conclusion}

The consumption of ultra-processed and minimally processed foods presented a magnitude to change the NS (from OW to OB), even when controlled by sociodemographic factors, physical activity, hypertension, and diabetes. Therefore, our findings can help to guide the population about the magnitude of the effects that the consumption of different types of foods can modify their health.

\section{Background}


Obesity (OB) remains a central global challenge with its incremental prevalence and incidence continuing to worry health-promoting agencies, such as the World Health Organization (WHO). Indeed, OB is related to many health conditions that have a trend to cluster between themselves reducing life expectancy up to 20 years [1]. The most frequent OB-related health conditions are diabetes mellitus, hepatic steatosis, hypertension, myocardial infarction, stroke, musculoskeletal and Alzheimer's diseases, depression, and some types of cancer [2].

It is important to highlight the narrow relationship between the occurrence of the above-mentioned diseases and the nutritional status (NS) [3-5]. There is evidence showing that the transition from overweight (OW) to OB represents a higher risk (compared to the transition normal weight to $\mathrm{OW}$ ) in the development of chronic diseases, morbidity, premature mortality, and health services burden $[5,6]$.

OB phenotype is a result of a complex net of genetic and environmental factors [3,4]. Behavioral factors are linked to daily living context and exert a crucial role on OB onset and development [2, 7]. Amongst others, dietary patterns might have a positive or a negative effect on nutritional status (NS) depending on the type of foods consumed [8-10]. In this sense, the quality of food consumed might be a pathway to understanding the transition of NS to OB [3-5].

The minimally processed foods (obtained from plants or animals, without big changes on your natural state until consumption) and the ultra-processed foods (high quantity of ingredients inserted in its formulation, passing for many industrial processes prior to consumption) are those that mostly impact on NS $[7,11,12]$. Indeed, high daily consumption of minimally processed foods is associated with a lower odd of $\mathrm{OB}$, metabolic syndrome, dyslipidemia, and gastrointestinal diseases $[11,13]$. Conversely, there are many studies showing associations between high daily consumption of ultra-processed foods and overweight (OW), OB, diabetes, hypertension, dyslipidemia, cardiovascular and respiratory diseases, stroke, breast cancer, depression, frailty, and premature mortality $[8,10,14]$. However, the available literature does not quantify the impact of the amount of food (in terms of the level of processing) on the odds for $\mathrm{OB}$ development. Recently published systematic reviews $[8,10]$ underline that the minimally processed and ultra-processed foods consumed are related to OB development, but the consumption itself (in terms of daily items) should be further determined to help to design public health campaigns against OB. Data on this topic is however lacking.

Therefore, the study aims to investigate the magnitude of the impact of ultra-processed food and minimally processed food consumption in the change of NS from OW to OB. We hypothesize that the minimally processed foods can decrease the odds of change on NS to OB; on the other hand, the ultraprocessed foods can present a well-marked increase in the odds of change of NS.

\section{Methods}

\section{Surveillance System for Risk Factors and Protection for Chronic Diseases by Telephone Survey}


The data used in this study is from the epidemiologic project named Surveillance of Risk Factors and Protection for Chronic Diseases by Telephone Survey (VIGITEL). The VIGITEL refers to a Surveillance System of Risk Factors for Chronic Non-Communicable Diseases supported by the Brazilian Ministry of Health.

Data was gathered with telephone interviews conducted between January and December 2019. Interviewers were under the supervision of the Brazilian Ministry of Health in partnership with the Group for Studies, Research and Practices in the Food Environment and Health, of the Federal University of Minas Gerais (GEPPAAS/UFMG) and the Research Center Epidemiological Studies in Nutrition and Public Health, University of São Paulo (NUPENS/USP).

The VIGITEL had a cross-sectional design and considered subjects (with at least 18 years old) living in one of the 26th Brazilian capitals or the Federal District, who have one fixed telephone line (Fig. 1). Free and informed consent was orally registered at the time of telephone contact. VIGITEL data are publicly available and can be requested for scientific reproducibility [15]. The VIGITEL protocol contemplated a general health status questionnaire plus food consumption, which can be viewed in the original project [15]. Answers were read for the subjects and electronically registered.

\section{Selection of subjects for this study}

For this particular study, the following inclusion criteria were age between 18- and 59-years and NS classified as $\mathrm{OW}$ or $\mathrm{OB}$.

\section{Measurements}

For this study, the variables of interest were those that could determine the change of NS from OW to OB. Therefore, the variables included in this study addressed characteristics of dietary pattern, sociodemographic characteristics, daily habits, use of licit drugs, and presence of health conditions.

\section{Weight, height, and BMI}

Weight and height were recorded to perform the BMI calculation (weight ${ }_{[\mathrm{kg}]} /$ height $_{[\mathrm{m}]}{ }^{2}$ ). The subjects with BMI of $25 \mathrm{~kg} / \mathrm{m}^{2}$ to $29.99 \mathrm{~kg} / \mathrm{m}^{2}$ were classified with $\mathrm{OB}$, whereas the subjects with $\mathrm{BMI}>30 \mathrm{~kg} / \mathrm{m}^{2}$ were classified with OB [3].

\section{Dietary pattern}

The dietary pattern was considered as daily consumption of minimally processed and ultra-processed foods (number of items consumed per day). The foods were stratified into groups of similar features (i.e., for minimally processed foods: grain legumes, fruits, breads) and the answers were given in a dichotomous way ('yes' or 'not') [14].

\section{Sociodemographic characteristics}

Chronologic age, sex, and years of education were determined via open-answered questions. 


\section{Physical activity and sedentary time}

The weekly physical activity level (PAL) was classified according to the WHO physical activity guidelines ( $\geq 150 \mathrm{~min}$ ). The amount of moderate to vigorous physical activity was computed based on the project's questionnaire, with answers to questions related to leisure, occupational activity, and transportation [15, 16]. Daily time spent watching TV and using cell phones, tablets, and computers was also computed.

\section{Use of licit drugs}

Smoking habits (as a number of cigarettes per week) and the presence of alcoholic beverages consumption ('yes' or 'not') also were considered.

\section{Health conditions}

The presence of arterial hypertension and diabetes was self-reported ('yes' or 'not') by the subjects.

\section{Statistical analysis}

Descriptive statistics (measures of central tendency and relative frequency) are presented to describe the sample. BMI was classified as quartiles and the absolute frequency of minimally processed and ultraprocessed foods was demonstrated for each quartile. Binary logistic regression was used to verify the associated factors with NS change (from OW to OB). The NS classification was considered as a dependent variable $(0=\mathrm{OW} ; 1=\mathrm{OB})$, dietary pattern as independent variable adjusted for covariables (demographic and socioeconomic characteristics, dietary pattern, PAL, sedentary time, use of licit drugs, and presence of health conditions). Odds ratio (OR) was reported to indicate the magnitude of risk of $\mathrm{OW} / \mathrm{OB}$. The $\mathrm{OR}$ of transition (OW to $\mathrm{OB}$ ) was extrapolated (multiplied) according to quartiles of minimally processed and ultra-processed food consumption. All analyzes were performed in SPSS, v. 20.0 (Inc., Chicago, IL, USA), with a previously established significance level $(a=5 \%)$. This manuscript has been produced by the requirements of the Strengthening the Reporting of Observational Studies in Epidemiology (STROBE) checklist for cross-sectional studies.

\section{Results}

Figure 1 depicts the study flowchart. From the initial potential 197.600 adults participants, 75.789 were eligible in terms of possession of a telephone line. Of those, 52.443 were interviewed, and 15.024 were classified as OB (5.406) or OW (9.618).

The descriptive statistics of total of subjects ( $n=15.024)$ classified with OW ( $n=9618 ; 64 \%$, being $55.1 \%$ women) and OB ( $n=5406 ; 36 \%$, being $57.1 \%$ male) are shown in Table 1 . The mean age was 42.7 years of OW subjects and 43.7 years of the $\mathrm{OB}$. For overall food consumption, there was a superior mean of minimally processed food $(O W=7.1 ; O B=6.8)$ compared to ultra-processed food $(O W=2.5 ; O B=2.6)(p$ $<0.001)$. 
Table 1. Descriptive analysis of overweight and obese participants in the project for surveillance of risk and protective factors for chronic diseases by telephone survey (VIGITEL). 


\begin{tabular}{|c|c|c|c|c|}
\hline \multirow[t]{2}{*}{ Variables } & \multicolumn{2}{|c|}{ Overweight $(n=9618)$} & \multicolumn{2}{|c|}{ Obesity $(n=5406)$} \\
\hline & $\begin{array}{l}\text { Mean } \pm \\
\text { SD }\end{array}$ & $95 \% \mathrm{Cl}$ & $\begin{array}{l}\text { Mean } \pm \\
\text { SD }\end{array}$ & $95 \% \mathrm{Cl}$ \\
\hline Age (Years) & $\begin{array}{l}42.7 \pm \\
11.4\end{array}$ & $\begin{array}{l}42.5 \text { to } \\
42.9\end{array}$ & $\begin{array}{l}43.7 \pm \\
10.8\end{array}$ & $\begin{array}{l}43.4 \text { to } \\
44.0\end{array}$ \\
\hline \multicolumn{5}{|l|}{ Sex } \\
\hline Male (\%) & \multicolumn{2}{|l|}{44.9} & \multicolumn{2}{|l|}{42.4} \\
\hline Female (\%) & \multicolumn{2}{|l|}{55.1} & \multicolumn{2}{|l|}{57.6} \\
\hline \multicolumn{5}{|l|}{ Scholarity } \\
\hline Years of study (Years) & $\begin{array}{l}12.7 \pm \\
4.2\end{array}$ & $\begin{array}{l}12.6 \text { to } \\
12.8\end{array}$ & $\begin{array}{l}12.0 \pm \\
4.5\end{array}$ & $\begin{array}{l}11.9 \text { to } \\
12.2\end{array}$ \\
\hline \multicolumn{5}{|l|}{ Anthropometry } \\
\hline Body mass (kg) & $\begin{array}{l}75.6 \pm \\
9.8\end{array}$ & $\begin{array}{l}75.4 \text { to } \\
75.8\end{array}$ & $\begin{array}{l}92.0 \pm \\
15.5\end{array}$ & $\begin{array}{l}91.6 \text { to } \\
92.4\end{array}$ \\
\hline Height (cm) & $\begin{array}{l}166.3 \pm \\
9.9\end{array}$ & $\begin{array}{l}166.1 \text { to } \\
166.5\end{array}$ & $\begin{array}{l}164.7 \pm \\
11.3\end{array}$ & $\begin{array}{l}164.4 \text { to } \\
165.0\end{array}$ \\
\hline $\mathrm{BMI}\left(\mathrm{kg} / \mathrm{m}^{2}\right)$ & $\begin{array}{l}27.2 \pm \\
1.4\end{array}$ & $\begin{array}{l}27.2 \text { to } \\
27.3\end{array}$ & $\begin{array}{l}33.8 \pm \\
4.1\end{array}$ & $\begin{array}{l}33.7 \text { to } \\
34.0\end{array}$ \\
\hline \multicolumn{5}{|l|}{ Food consumption (day) } \\
\hline Minimally processed (food/day) & $\begin{array}{l}7.1 \pm \\
2.1\end{array}$ & 7.1 to 7.1 & $6.8 \pm 2.1$ & 6.7 to 6.8 \\
\hline Q1 (food/day) & 1 & & & \\
\hline Q2 (food/day) & 6 & & & \\
\hline Q3 (food/day) & 7 & & & \\
\hline Q4 (food/day) & 8 & & & \\
\hline Ultra-processed (food/day) & $\begin{array}{l}2.5 \pm \\
1.9\end{array}$ & 2.5 to 2.5 & $2.6 \pm 1.9$ & 2.5 to 2.6 \\
\hline Q1 (food/day) & 1 & & & \\
\hline Q2 (food/day) & 1 & & & \\
\hline Q3 (food/day) & 2 & & & \\
\hline Q4 (food/day) & 4 & & & \\
\hline \multicolumn{5}{|c|}{ Physical activity and sedentary time } \\
\hline $\mathrm{PAL} \geq 150 \mathrm{~min} /$ week (\%) & 59.5 & & 51.5 & \\
\hline
\end{tabular}




\begin{tabular}{|c|c|c|c|c|}
\hline Watch TV (hours/day) & $\begin{array}{l}2.1 \\
\pm 1.4\end{array}$ & 2.0 to 2.1 & $2.2 \pm 1.5$ & 2.2 to 2.3 \\
\hline Habit of watching TV $\geq 3$ hours/day (\%) & 19.9 & & 24.2 & \\
\hline $\begin{array}{l}\text { Use of computers, tablets and cell phones in free } \\
\text { time (\%) }\end{array}$ & 79.8 & & 78.6 & \\
\hline $\begin{array}{l}\text { Use of computers, tablets and cell phones in free } \\
\text { time (hours/day) }\end{array}$ & $\begin{array}{l}1.8 \pm \\
1.6\end{array}$ & 1.8 to 1.9 & $1.9 \pm 1.6$ & 1.8 to 1.9 \\
\hline Total screen time $\geq 3$ hours/day (\%) & 62.9 & & 64.5 & \\
\hline \multicolumn{5}{|l|}{ Use of licit drugs } \\
\hline Cigarette consumption (\%) & 6.8 & & 5.9 & \\
\hline Cigarette consumption (cigarettes/week) & $\begin{array}{l}4.8 \pm \\
23.8\end{array}$ & 4.4 to 5.3 & $\begin{array}{l}4.3 \pm \\
23.6\end{array}$ & 3.6 to 4.9 \\
\hline Alcohol consumption (\%) & 44.3 & & 41 & \\
\hline \multicolumn{5}{|l|}{ Health conditions } \\
\hline Hypertension (\%) & 22.4 & & 39.1 & \\
\hline Diabetes (\%) & 5.3 & & 9.8 & \\
\hline
\end{tabular}

Abbreviations: $\mathrm{BMI}=$ body mass index; $\mathrm{Q}=$ Quartile; $\mathrm{PAL}=$ Physical activity level

Figure 2 depicts the relationship of BMI quartiles with the amount of daily food consumption (minimally or ultra-processed). There is an inverse relationship between the BMI quartiles and the number of minimally processed foods consumed (higher the BMI, lower the consumption). The same happens for ultra-processed foods, but the relationship is positive (except for the $2^{\text {nd }}$ quartile of $\mathrm{BMI}$ ).

Table 2 presents the OR for change of NS (from OW to OB) with consumption of minimally processed food and ultra-processed food. The crude model represents the inclusion of dietary patterns only as an explicative variable. Then the Model 1 includes the dietary pattern plus demographic and socioeconomic characteristics, and Model 2 the same variables of Model 1 plus daily habits, use of licit drugs, and presence of pathologies.

Table 2. Binary logistic regression model with the influence of minimally processed and ultra-processed food consumption in the change of nutritional status (form overweight to obesity).

\begin{tabular}{|c|c|c|c|}
\hline Factors & Crude (OR) & Model 1 (OR) & Model 2 (OR) \\
\hline $\begin{array}{l}\text { Daily consumption of minimally } \\
\text { processed foods }\end{array}$ & $\begin{array}{l}.932(.917 \text { to } \\
.947)^{*}\end{array}$ & $\begin{array}{l}.934(.919 \text { to } \\
.949)^{*}\end{array}$ & $\begin{array}{l}.941(.925 \text { to } \\
.957)^{\star}\end{array}$ \\
\hline $\begin{array}{l}\text { Daily consumption of ultra-processed } \\
\text { foods }\end{array}$ & $\begin{array}{l}1.025(1.007 \text { to } \\
1.043)^{\#}\end{array}$ & $\begin{array}{l}1.041(1.023 \text { to } \\
1.061)^{\star}\end{array}$ & $\begin{array}{l}1.037(1.018 \text { to } \\
1.057)^{\star}\end{array}$ \\
\hline
\end{tabular}


\#: $p<0.05 ; *: p \leq 0.001$. Model 1: adjusted for age, sex, and study years; Model 2: adjusted for age, sex, study years, physical activity levels, sedentary time, alcohol and cigarette consumption, presence of hypertension and diabetes. OR: Odds Ratio.

All models had statistical significance to explain the NS change (crude: $X^{2}=160.790$ [p<0.001]; Model 1: $X^{2}=1.563,473$ [ $\left.p<0.001\right]$; and Model 2: $\left.X^{2}=37.707,195[p<0.001]\right)$. Even considering Model 2, adjusted by conditions (age, sex, years of education, PAL, sedentary time, alcohol, and cigarette consumption, presence of hypertension and diabetes), the consumption of minimally processed (OR=0.941) and ultraprocessed $(O R=1.037)$ foods continued to be related to the NS change. For each minimally processed food consumed per day, there is a reduction of $5.9 \%$ in the chance of OB occurrence. Conversely, for each ultra-processed food consumed per day, there is an increase of $3.7 \%$ in the chance of OB occurrence.

Figure 3 reports the relationship interquartile of food consumption (minimally and ultra-processed) with the percentage of change of NS. Subjects had higher odds against OB development when belonging to the highest quartiles of minimally processed food consumption ( $Q 3=41.3 \%$ to $Q 4=47.2 \%$ ). Subjects in the lower quartiles (Q1=3.7\% and Q2=3.7\%) of ultra-processed foods are less likely to change their NS to OB, but as the consumption of ultra-processed foods increases, the chances of OB are higher.

\section{Discussion}

As far as we know, this is the first study quantifying the magnitude of minimally processed and ultraprocessed food consumption on $\mathrm{OB}$ development. In addition to the already known risk factors (years of education, PAL, time spent watching TV and/or gadgets, presence of health conditions) [17-20], our main findings elucidate the influence that the quality of food consumption is crucial on OB development (Table 2). For each minimally processed food consumed per day, the risk of worsening of NS decreases by $5.9 \%$ whereas, for each ultra-processed food consumed per day, the odds of getting OB increases by $3.7 \%$.

Beyond the quantity of intake of carbohydrates, the consumption of minimally processed food influences absorption and storage of micronutrients [11]. These foods (e.g., fruits, vegetables, and grains) are characterized for less volume and energetic density per portion [20]. In addition, the presence of vitamins, minerals, and fibers, contributes to reduction of metabolic diseases risk $[11,13]$. Therefore, the consumption of minimally processed food decreases considerably the chances of getting $O B[3,13,21]$. For ultra-processed food consumption, the presence of $\mathrm{OB}$ is explained by the high volume and energetic density usually present in these foods [20]. For example, sodas, ice creams, and chocolates contain high levels of sucrose, sodium, and trans-fat (in the case of ice cream) $[8,10,12,20,22,23]$. Thus, as shown by our findings, to avoid weight gain and get a caloric balanced diet, the consumption of ultra-processed foods must be avoided.

The quartiles of BMI about food consumption (minimally processed and ultra-processed) shown in our study are noteworthy. The inverse relationship between the consumption of minimally processed foods and BMI elucidates the reactive behavior of subjects as NS changes [24]. According to Schulte et al 
(2019), based on a protocol study with image analysis, this phenomenon can be explained by an imbalance in the neural responses manifested in the region of the superior frontal gyrus of individuals with OW/OB. This imbalance would influence the moment of selecting foods to consume and the type of food regarding the level of processing (decision-making). Furthermore, the type of food can decrease (or increase) dopamine responses and affect the gustatory reward mechanisms of food [25]. That is, the individual would tend not to choose the minimally processed food because the altered dopaminergic pathways would impair the feeling of "craving" [26]. While the reward mechanism does not view minimally processed food as palatable and pleasant $[26,27]$.

On other hand, the relation of BMI quartiles and the ultra-processed food consumption tended to proportionality, except for Quartile 2 (Figure 2). When a subject notes that his/her BMI is enlarged, the search for strategies to reduce body mass becomes greater, adopting the pre-contemplation stage of change $[28,29]$. However, the period of adherence to healthy habits (exercise/eating) is harmed by the impact caused by this rapid change (when not guided by health professionals), able to cause compulsive and reactive behaviors on food choice [25]. The chronic consumption of ultra-processed food induces an emotional trigger [27], forcing the subject to return to excessive food consumption and increasing his/her chances of $O B$ developing. In this sense, the transition across $O W$ and $O B$ must be well established from stages of change, decreasing the occurrence of a fast imbalance in eating behavior [20].

Our analysis has strengths. A large number of participants from all regions of Brazil comprises a nationally representative sample. Collecting data through telephone interviews conducted by previously trained staff and adjusting for a wide range of important risk factors minimized the potential impact of residual confounding. The telephone interview allowed for clear and precise explanations about each question, avoiding misunderstandings. As far as we know, this is the first community-based study to suggest that the magnitude of consumption of ultra-processed foods modifies the chances of $O B$ in adults.

This study also has limitations that must be considered. The cross-sectional design does not allow establishing cause-effect relationships. Therefore, extrapolating our findings to other populations to confirm their clinical relevance to different sociodemographic conditions should be made with caution. Another limitation involves the form of assessment of physical activity, subjectively performed with questionnaires that tend to overestimate moderate/vigorous physical activity and underestimate sitting time [30]. However, for population studies, the questionnaire is a useful low-cost tool for characterizing a given sample [31]. The absence of information regarding total daily energy intake is an important study limitation. It was impossible to apply a dietary questionnaire by phone due to logistical reasons (i.e., length of phone calls and participants' comprehension of the questionnaire). Indeed, Brazil has a huge geographical region with many specific regional dietary products. Nevertheless, the number of foods consumed in one day does not inform with accuracy the amount of energy ingested, but the number of ultra-processed foods daily consumed can represent a high effect on weight gain, regardless of the daily calories ingested $[8,20]$. 
As practical implications of our findings, health professionals are responsible for guiding populations' nutritional habits. Thus, they must emphasize the positive and negative impacts related to minimally processed and ultra-processed food, respectively, on OB control. Numerically, demonstration of the magnitude that these two types of foods consumption exert on NS change might help to improve populations eating behavior from the pre-contemplation phase [28] (who still doesn't consider making a change) to the contemplation on the identification of behavior and possibility of change of dietary habits [32]. For example, if a subject with $\mathrm{OW}$ increases his/her frequency of daily consumption up to 10 ultraprocessed foods, this person will have an additional chance of $37 \%$ to reach the OB category. On the other hand, if this person consumes 10 minimally processed foods, the chances of evolution to OB would be reduced by $59 \%$. This quantitative application reinforces the arguments that the occurrence of $O B$ can be understood through the magnitude of foods (minimally processed and ultra-processed) to change the NS.

As implications for research, our findings support strategies of quantification of dietary patterns for other populations. Furthermore, future research should investigate which ultra-processed foods have a greater impact on $\mathrm{OB}$ development establishing a more objective relationship in the magnitude of quantification of each type of food and its centesimal composition of nutrients.

\section{Conclusions}

The consumption of ultra-processed and minimally processed foods presented magnitudes to change the NS (from OW to OB), even when controlled by sociodemographic factors, physical activity, hypertension, and diabetes. Although $\mathrm{OB}$ is multifactorial, knowing the magnitude of the contribution of each minimally processed and ultra-processed food can help to design effective intervention strategies. We present measurable mean estimates to assist health professionals in changing population eating behavior. Our findings can help to guide the population about the magnitude of the effects that the consumption of different types of foods can bring about on their health.

\section{Declarations}

Ethics approval and consent to participate

All participants volunteered for the study, were informed about the scope of the study, and provided orally consent at the time of telephone contact. The VIGITEL project was approved by the National Commission on Ethics in Research for Human Beings of the Ministry of Health (CAAE: 65610017.1.0000.0008). The data used in this manuscript were collected from the online and open access database from VIGITEL (http://svs.aids.gov.br/download/Vigitel/), which justifies the absence of the permission of the Research Ethics Committee. The authors confirm that all methods were carried out in accordance with declaration of Helsinki. 
Consent for publication

Not applicable.

Availability of data and materials

All data are public and can be found on the official website of the study https://www.gov.br/saude/ptbr/assuntos/saude-de-a-a-z/v/vigitel-1/vigitel.

Competing interests

The authors declare that they have no competing interests.

Funding

This study was supported by funding from CAPES, Coordination for the Improvement of Higher Education Personnel (finance Code 001, 88887.371516/2019-00 to DRLM, and 88887.593242/2020-00 to PPA), CNPq, National Council for Scientific and Technological Development (finance code 142248/2018-5 to PPA). The funding body had no role in the design of the study and collection, analysis, and interpretation of data or writing of the manuscript.

Authors' contributions

LSLS and DRLM: Conceptualization; Roles/Writing - original draft; PPA: Data curation, Visualization; LSLS and PPA: Methodology, LSLS and PPA: Formal analysis; DRLM: Software, JM: Funding acquisition, Supervision; LB, RGA; DFB; ACRV; ASC; and MD: Writing - review \& editing; DRLM: Validation; and JM: Project administration, Resources. All authors have read and approved the manuscript.

Acknowledgements

Not applicable.

\section{References}

1. Fontaine KR, Redden DT, Wang C, Westfall AO, Allison DB. Years of life lost due to obesity. JAMA. 2003;289:187-193. https://doi.org/10.1001/jama.289.2.187

2. Blüher M. Obesity: Global epidemiology and pathogenesis. Nature Reviews Endocrinology. 2019;15:288-298. https://doi.org/10.1038/s41574-019-0176-8

3. World Health Organization. Obesity: Preventing and managing the global epidemic: report of a WHO consultation. Geneva: WHO; 2000.

4. World Health Organization. Global status report on noncommunicable diseases. Geneva: WHO; 2014.

5. Jensen MD, Ryan DH, Apovian CM, et al. 2013 AHA/ACC/TOS guideline for the management of overweight and obesity in adults: a report of the American College of Cardiology/American Heart 
Association Task Force on Practice Guidelines and The Obesity Society. Circulation. 2014;24:S102138. doi: 10.1161/01.cir.0000437739.71477.ee.

6. Batsis JA, Huyck KL, Bartels SJ. Challenges with the Medicare obesity benefit: practical concerns \& proposed solutions. J Gen Intern Med. 2015;30:118-122. doi: 10.1007/s11606-014-3031-6.

7. Bhupathiraju SN, Hu FB. Epidemiology of Obesity and Diabetes and Their Cardiovascular Complications. Circulation Research. 2016;118:1723-1735. https://doi.org/10.1161/CIRCRESAHA.115.306825

8. Martí A, Calvo C, Martínez A. Ultra-processed food consumption and obesity-a systematic review. Nutricion Hospitalaria. 2021;38: 177-185. https://doi.org/10.20960/nh.03151

9. Monteiro CA, Moubarac JC, Cannon G, Ng SW, Popkin B. Ultra-processed products are becoming dominant in the global food system. Obesity Reviews: An Official Journal of the International Association for the Study of Obesity. 2013;14:21-28. https://doi.org/10.1111/obr.12107

10. Askari M, Heshmati J, Shahinfar $\mathrm{H}$, et al. Ultra-processed food and the risk of overweight and obesity: a systematic review and meta-analysis of observational studies. Int J Obes. 2020;44:2080-2091. https://doi.org/10.1038/s41366-020-00650-z.

11. Fardet A. Minimally processed foods are more satiating and less hyperglycemic than ultra-processed foods: A preliminary study with 98 ready-to-eat foods. Food \& Function. 2016;7:2338-2346. https://doi.org/10.1039/C6F000107F

12. Rauber F, Steele EM, Louzada MLC, Millett C, Monteiro CA, Levy RB. Ultra-processed food consumption and indicators of obesity in the United Kingdom population (2008-2016). PLoS ONE. 2020;15:e0232676. https://doi.org/10.1371/journal.pone.0232676

13. Kopf JC, Suhr MJ, Clarke J, et al. Role of whole grains versus fruits and vegetables in reducing subclinical inflammation and promoting gastrointestinal health in individuals affected by overweight and obesity: A randomized controlled trial. Nutrition Journal. 2018;17:72. https://doi.org/10.1186/s12937-018-0381-7

14. Lane MM, Davis JA, Beattie S, et al. Ultraprocessed food and chronic noncommunicable diseases: A systematic review and meta-analysis of 43 observational studies. Obesity Reviews: An Official Journal of the International Association for the Study of Obesity. 2021;22:e13146. https://doi.org/10.1111/obr.1314614

15. Brasil. Vigitel Brasil 2019: vigilância de fatores de risco e proteção para doenças crônicas por inquérito telefônico. Brasilia: Ministério da Saúde; 2020.

16. World Health Organization. Global recommendations on physical activity for health. Geneva: WHO; 2010.

17. Rosiek A, Maciejewska NF, Leksowski K, Rosiek-Kryszewska A, Leksowski Ł. Effect of Television on Obesity and Excess of Weight and Consequences of Health. International Journal of Environmental Research and Public Health. 2015;12:9408-9426. https://doi.org/10.3390/ijerph120809408

18. Cohen JB. Hypertension in Obesity and the Impact of Weight Loss. Current Cardiology Reports. 2017;19:98. https://doi.org/10.1007/s11886-017-0912-4 
19. Mottalib A, Kasetty M, Mar JY, Elseaidy T, Ashrafzadeh S, Hamdy O. Weight Management in Patients with Type 1 Diabetes and Obesity. Current Diabetes Reports. 2017;17:92.

https://doi.org/10.1007/s11892-017-0918-8

20. Hall KD, Ayuketah A, Brychta R, et al. Ultra-Processed Diets Cause Excess Calorie Intake and Weight Gain: An Inpatient Randomized Controlled Trial of Ad Libitum Food Intake. Cell Metabolism. 2019;30:67-77. https://doi.org/10.1016/j.cmet.2019.05.008

21. World Health Organization. Diet, nutrition and the prevention of chronic diseases. Geneva: WHO; 2003.

22. Canhada SL, Luft VC, Giatti L, et al. Ultra-processed foods, incident overweight and obesity, and longitudinal changes in weight and waist circumference: The Brazilian Longitudinal Study of Adult Health (ELSA-Brasil). Public Health Nutrition. 2019;23:1076-1086.

https://doi.org/10.1017/S1368980019002854

23. Frieler RA, Vigil TM, Song J, Leung C, Lumeng CN, Mortensen RM. High-fat and high-sodium diet induces metabolic dysfunction in the absence of obesity. Obesity (Silver Spring). 2021;00:1-14. https://doi. org/10.1002/oby.23264

24. Melo ISV, Costa CACB, Santos JVLD, Santos AFD, Florêncio TMMT, Bueno NB. Consumption of minimally processed food is inversely associated with excess weight in adolescents living in an underdeveloped city. PLoS One. 2017;30:e0188401. doi: 10.1371/journal.pone.0188401.

25. Schulte EM, Yokum S, Jahn A, Gearhardt AN. Food cue reactivity in food addiction: A functional magnetic resonance imaging study. Physiol Behav. 2019;208:112574. doi:

10.1016/j.physbeh.2019.112574.

26. Volkow ND, Wang GJ, Baler RD. Reward, dopamine and the control of food intake: implications for obesity. Trends Cogn Sci. 2011;15:37-46. doi: 10.1016/j.tics.2010.11.001.

27. Wu M, Brockmeyer T, Hartmann M, Skunde M, Herzog W, Friederich HC. Reward-related decision making in eating and weight disorders: A systematic review and meta-analysis of the evidence from neuropsychological studies. Neurosci Biobehav Rev. 2016;61:177-196. doi:

10.1016/j.neubiorev.2015.11.017.

28. Lechner L, Brug J, De Vries H, van Assema P, Mudde A. Stages of change for fruit, vegetable and fat intake: consequences of misconception. Health Education Research. 1998;13:1-11. https://doi.org/10.1093/her/13.1.1-a

29. Macqueen CE, Brynes AE, Frost GS. Treating Obesity: Can the Stages of Change Model Help Predict Outcome Measures? Journal of Human Nutrition and Dietetics. 1999;12:229-236. https://doi.org/10.1046/j.1365-277x.1999.00162.x

30. Lee PH, Macfarlane DJ, Lam TH, Stewart SM. Validity of the International Physical Activity Questionnaire Short Form (IPAQ-SF): a systematic review. Int J Behav Nutr Phys Act. 2011;21:115. doi: 10.1186/1479-5868-8-115.

31. Washburn RA, Smith KW, Jette AM, Janney CA. The Physical Activity Scale for the Elderly (PASE): Development and evaluation. Journal of Clinical Epidemiology. 1993;46:153-162. 
https://doi.org/10.1016/0895-4356(93)90053-4

32. Ling AMC, Horwath C. Defining and Measuring Stages of Change for Dietary Behaviors: Readiness to Meet Fruit, Vegetable, and Grain Guidelines among Chinese Singaporeans. Journal of the American Dietetic Association. 2000;100:898-904. https://doi.org/10.1016/S0002-8223(00)00261-3.

\section{Figures}

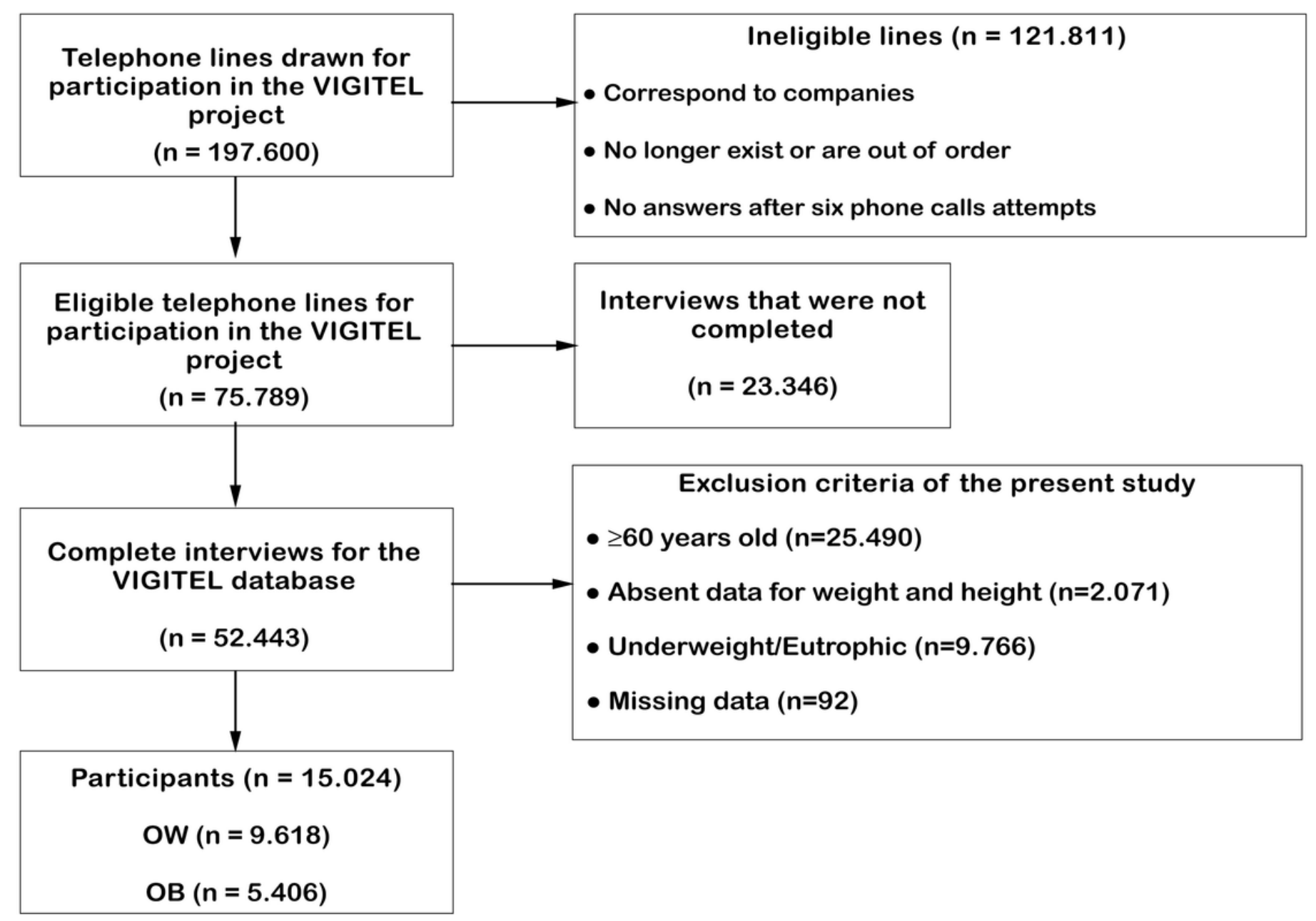

Figure 1

Flowchart of selection of subjects for this study. Abbreviations: $\mathrm{OW}=0$ verweight; $\mathrm{OB}=0$ besity. 

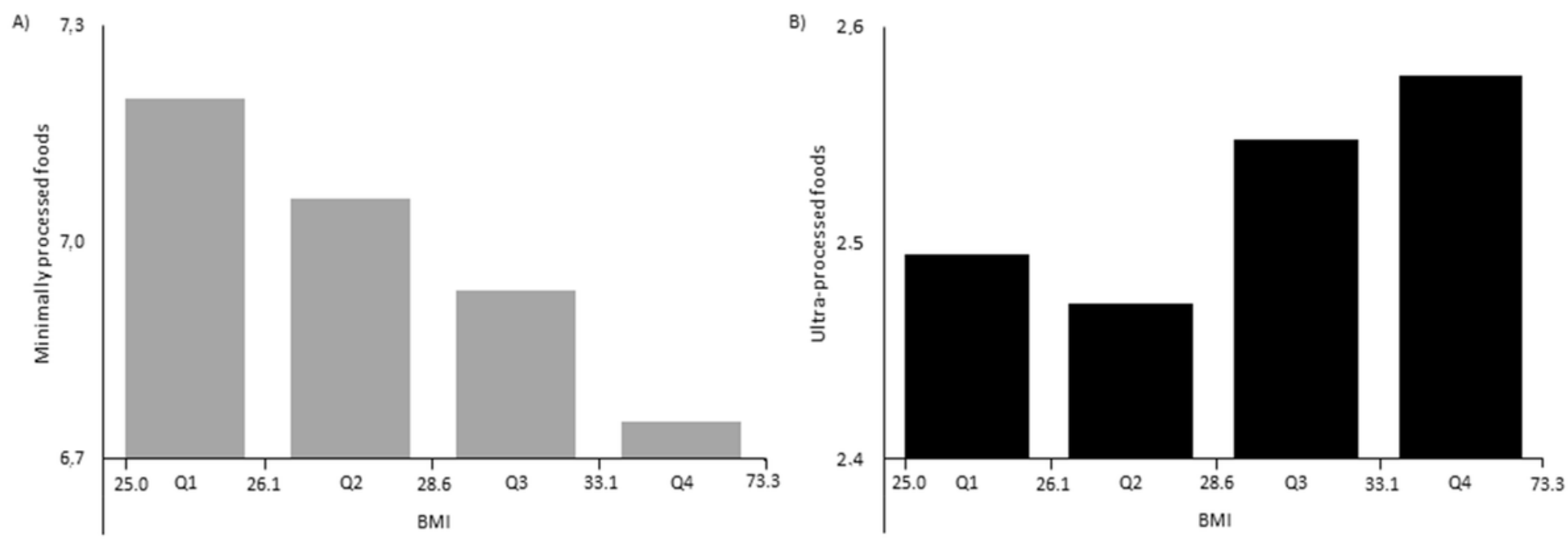

Figure 2

Quartiles of body mass index (BMI) and absolute frequency of minimally processed $(\mathrm{A})$ and ultraprocessed (B) food consumption.
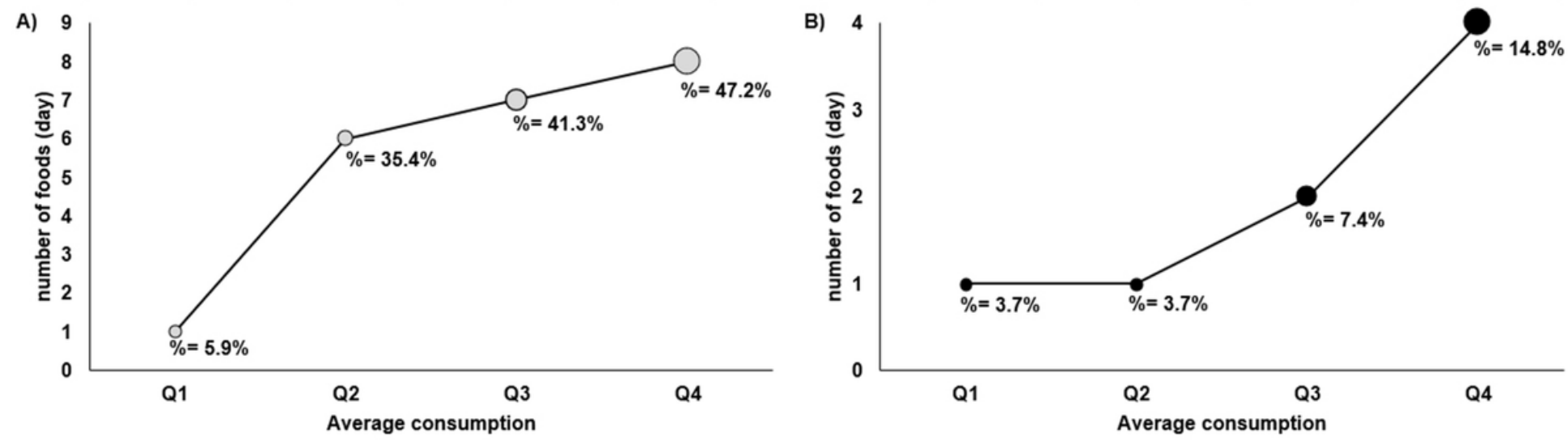

Figure 3

Percentage of chance of changing nutritional status (overweight [OW] to obesity [OB]) for each quartile (Q) of minimally processed (A) and ultra-processed (B) food consumption.

Note: Figure 3A represent negatives $\mathrm{OR}$ for $\mathrm{OB}$ development, and Figure 3B a positive $\mathrm{OR}$ for $\mathrm{OB}$ development.

\section{Supplementary Files}

This is a list of supplementary files associated with this preprint. Click to download.

- graphicalabstract.tif 